\title{
Studies on Decomposition of Banana Leaf and Mixture of Cattle Dung and Urine by Thermophilic Coprophilous Fungi
}

\author{
Ajmera Shanthipriya*†, Sana Shanawaz* and Sivadevuni Girisham** \\ *†Department of Microbiology, Palamuru University, Mahabubnagar-509001, Telangana, India \\ **Department of Microbiology, Kakatiya University, Warangal-506009, Telangana, India \\ $†$ Corresponding author: Ajmera Shanthipriya; sreeja.poorvi@gmail.com
}

Nat. Env. \& Poll. Tech.

Website: www.neptjournal.com

Received: 01-09-2019

Accepted: 18-09-2019

\section{Key Words:}

Banana leaf; Cattle dung;

Thermophilic coprophilous

fungi; Soil fertility

\begin{abstract}
In this study, the microbial population responsible for decomposition of banana leaf with dung and urine of cattle (cow and sheep used here) was isolated, identified, and their incidence calculated. During this study, significant changes were observed in different physio-chemical properties (temperature, $\mathrm{pH}$, moisture content, humidity, ash content, total organic carbon, total nitrogen content, phosphorus) of decomposing material which focuses particularly on the role of thermophilic coprophilous fungi in reducing the time for decomposition. It also gives a clear demonstration of various effects of different environmental conditions on the microbial population during the process of decomposition. The decomposition product thus obtained was found to be rich in organic phosphorous and nitrogen, raising our hopes for a successful implementation of it in daily agricultural practices.
\end{abstract}

\section{INTRODUCTION}

Dung has an ecological community of microorganisms which supports the growth of thermophilic coprophilous fungi mainly because of its higher nitrogen content, $\mathrm{pH}$ and moisture content when compared with other substrates utilized by fungi (Webster 1970). Microbial changes during the decomposition of leaves have been reported by Hankin et al (1975), Sofia Duarte et al. (2009) and Manoharachary et al. (2014). Thermophilic coprophilous fungi are believed to contribute significantly to the rate of decomposition (Ross \& Harris 1983, Richardson 2002, Masunga et al. 2006). Generally, decomposition involves both mesophilic and thermophilic microorganisms. The optimal temperature range for thermophilic coprophilous fungi for growth and sporulation is $40-50^{\circ} \mathrm{C}$. Temperature, oxygen, $\mathrm{C} / \mathrm{N}$ ratio and moisture are important factors which affect composting (Waksman \& Cordon 1939). The composition of plant residues changes during decomposition. The final products of their decomposition include carbon dioxide, water, energy, microbial biomass, inorganic nutrients and re-synthesized organic carbon compounds such as humus, phenolics, celluloses, hemicelluloses and lignin. Under aerobic conditions, microbial decomposition results in a release of $\mathrm{CO}_{2}$. Under anaerobic or oxygen-limited conditions, anaerobic decomposers produce organic acids (Liu et al. 2006, Jianru 2013).

In the succession of dung, urine and banana leaf residues with thermophilic coprophilous fungi, the temperature in- creased continuously up to $36^{\circ} \mathrm{C}-50^{\circ} \mathrm{C}$. This group of fungi grows above $20^{\circ} \mathrm{C}-60^{\circ} \mathrm{C}$ (Rosenberg et al. 1972, Vijay \& Pathak (2014). In previous reports, the authors were concerned about the composition and dynamics of the microflora during the decomposition of different wastes like garbage and plant material, organic wastes (Beffa et al. 1996, Atkinson et al. 1997, Donkova et al. 2008 \& Ghaudhry et al. 2013) and animal manure on vermicomposting of mixed leaves litter (Viji \& Neelanarayanan 2015).

The populations of thermophilic and mesophilic microorganisms have been identified during decomposition. Monitoring of the microbial succession is very important in the effective management of the decomposition process as microbes play a key role in the process and the appearance of some microorganisms reflect the quality of maturing compost. Decomposition of organic matter by microbial activity is beneficial to mankind (Manoharachary et al. 2014).

Decomposition of fresh plant materials by microbes releases additional nitrogen and converts organic nitrogen to available forms. The pattern and timing of mineralization depend on the quality of residue, $\mathrm{C} / \mathrm{N}$ ratio, temperature, moisture content and method of incorporation (Swift et al. 1979). Ammonification occurs when organic matter is broken down into simpler amino compounds. Nitrogen is released in the form of ammonia through enzymatic digestion of bacteria and fungi, and then is dissolved in the soil solution as ammonium $\left(\mathrm{NH}_{4}^{+}\right)$. Plants can use $\mathrm{NH}_{4}^{+}$, although most nitrogen uptake is in the nitrate $\left(\mathrm{NO}_{3}{ }^{-}\right)$form. 


\section{MATERIALS AND METHODS}

Yeast extract, starch agar-agar and all other chemicals were purchased from HiMedia Laboratories Pvt Ltd., Mumbai, India. Cow dung and urine, sheep dung and urine and banana leaves were collected from Warangal, Telangana, India.

The decomposition of banana leaves by thermophilic fungi was studied by the method suggested by Joshi \& Thakre (1992). Banana leaves were chopped with the help of a chopping machine making its length to $5-6 \mathrm{~cm}$. Five $\mathrm{kg}$ of leafy biomass was well soaked in water and placed under the direct sunshade of a tree and laboratory conditions for degradation. Replicate sets were employed and repeated twice. The banana leaf material was subjected to the following treatments:

Banana leaf $(5 \mathrm{~kg})$ with water $(1000 \mathrm{~mL})$ was taken as control and banana leaf $(3 \mathrm{~kg})+$ cow dung $(2 \mathrm{~kg})+$ urine $(1000 \mathrm{~mL})$ and banana leaf $(3 \mathrm{~kg})+$ sheep dung $(2 \mathrm{~kg})+$ urine $(1000 \mathrm{~mL})$ as experimental sets. The observation was made for 6 months. The decomposing leaf material was analysed for its association of thermophilic fungi at monthly intervals. Simultaneously, physico-chemical changes in decomposed leaf were also analysed. The presence of thermophilic fungi was analysed by serial dilution and paired plate method (Cooney \& Emerson 1964) using the medium composition of starch, 30g; yeast extract, $5.0 \mathrm{~g} ; \mathrm{MgSO}_{4} .7 \mathrm{H}_{2} \mathrm{O}, 0.5 \mathrm{~g} ; \mathrm{K}_{2} \mathrm{H}$ $\mathrm{PO}_{4}, 1.0 \mathrm{~g}$; agar-agar, $20 \mathrm{~g}$, and distilled water $1000 \mathrm{~mL}$. The isolated strains were identified based on the morphological characters (Mouchacca 1997).

Temperature: Temperature of the decomposing leaf in pits was determined at the time of analysis for the thermophilic fungi. The thermometer was inserted into the decomposing material by removing the upper layer of the pit and temperature was recorded in ${ }^{\circ} \mathrm{C}$.

pH: Ten grams of the decomposing leaf litter was taken and cut into small pieces in $100 \mathrm{~mL}$ of distilled water and shaken for 30 minutes. The $\mathrm{pH}$ of the decomposing leaf litter suspension was determined with the help of Elico pH meter.

Moisture: 100 grams of the decomposing leaf of banana was dried at $105^{\circ} \mathrm{C}$ for 48 hours followed by cooling in desiccators and weighed to a constant weight and moisture was expressed in percentage of weight loss.

Humidity: Relative humidity $(\mathrm{RH})$ is the ratio of the partial pressure of water vapour to the equilibrium vapour pressure of water at a given temperature. It depends on temperature and the pressure of the system of interest.

Ash content: Total ash content of decomposing banana leaf was estimated by the method suggested by Ward \& Johnston (1962). Two grams of the oven-dried sieved sample of decomposing leaf material was weighed into porcelain crucible and kept in a muffle furnace at $558^{\circ} \mathrm{C}$ for 2 hours and weighed to a constant weight after cooling the sample in a desiccator and expressed in $\mathrm{mg}$.

Organic carbon (titration method): Estimation of organic carbon was made by Walkley-Black titration method. $0.1 \mathrm{~mL}$ of sieved sample was taken in 500mL Erlenmeyer flask add $20 \mathrm{~mL}$ of $1 \mathrm{~N}$ potassium dichromate and stirred and $20 \mathrm{~mL}$ of concentrated $\mathrm{H}_{2} \mathrm{SO}_{4}$ was added and stirred (Bailey et al. 1992). Above mixture was allowed to stand for 30 minutes followed by addition of $200 \mathrm{~mL}$ of distilled water and $10 \mathrm{~mL}$ orthophosphoric acid. Before titration with ferrous ammonium sulphate, $1 \mathrm{~mL}$ of diphenylamine was added and titration was done till the colour changed blue to green.

Total nitrogen: Colorimetric method of Wolf (1947) improvised by Ward \& Johnson (1962) was employed for estimating the total amount of nitrogen in decomposing banana leaf material. One hundred grams of leaf material was digested in a Kjeldahl flask and a yellow colour was developed with Nessler's solution whose intensity was measured at $480 \mathrm{~nm}$ with the help of a colorimeter. The amount of nitrogen was calculated from the standard curve. The total protein nitrogen was also calculated by multiplying the total nitrogen with a factor of 6.3 .

\section{RESULTS AND DISCUSSION}

\section{Succession of the Fungi on Cow Dung}

The succession of thermotolerant and thermophilic coprophilous fungi in the decomposing mixture of cow dung and urine with banana leaf (CDUB), and banana leaf (BL) without dung were studied and their incidence, frequency and abundance results were recorded (Table 1). It reveals that the incidence of different fungi in decomposing CDUB and BL varied with the progress of decomposition. Among all, 13 species belonging to 9 genera of fungi were involved in decomposing CDUB \& BL. M. pulchuella followed by $H$. insolens and $S$. thermophilum were dominant in decomposing CDUB. A. nidulans was active at early stages of decomposition but disappeared completely as their population increased later.

The least incidence $\%$ was recorded with Torulla thermophila, Cheatomium v. coprophiles followed by A. nidulans. Rest of the species were found to be intermediate in their incidence, while M. pulchuella was recorded with the highest frequency followed by $R$. arrhizus, $R$. pusillus and $S$. thermophilum, all of them similar in the percentage of frequency, with differing incidence. M. pulchuella was recorded with the highest abundance followed by Acremonium thermophilum and S. thermophilum. 


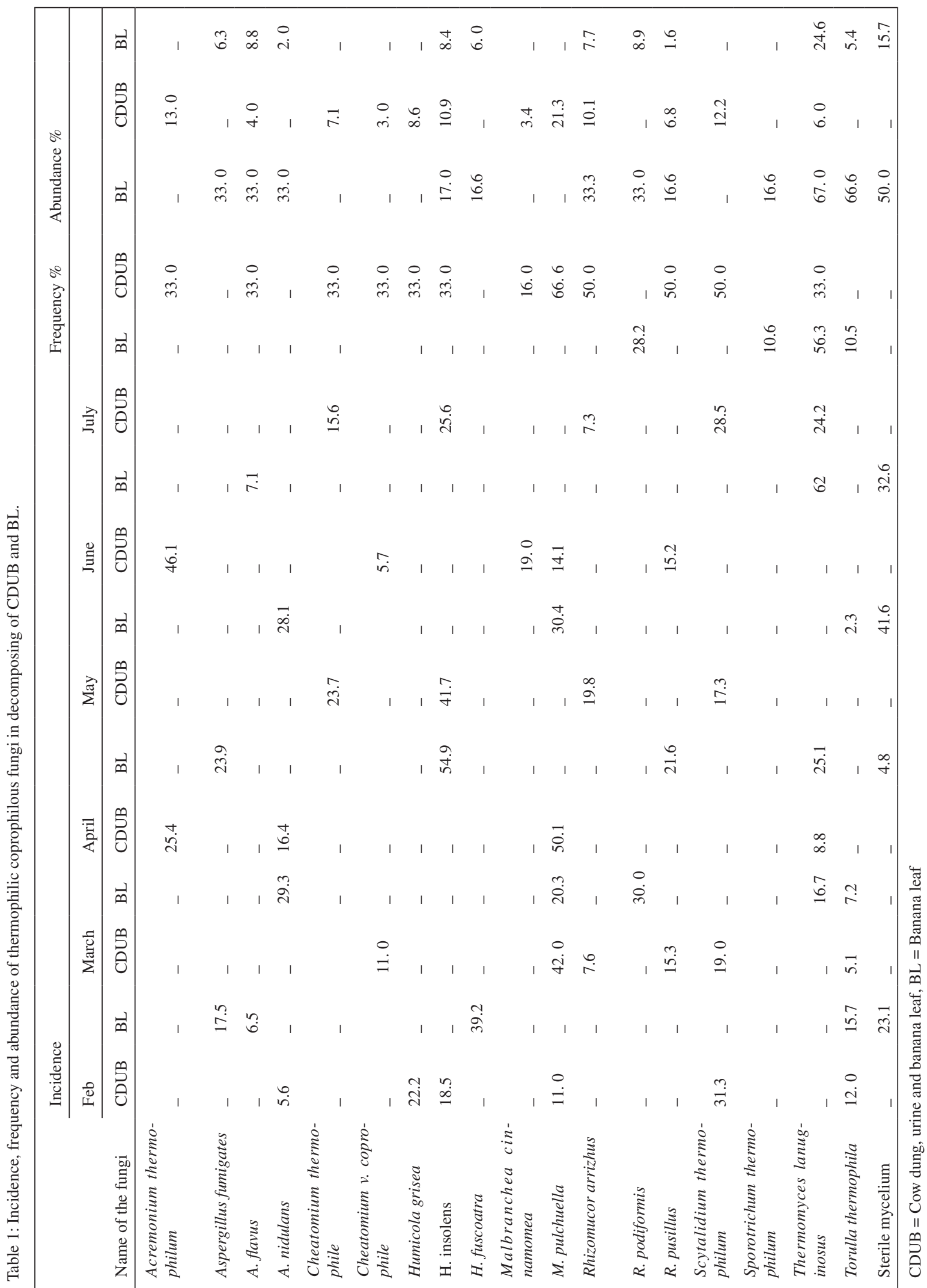


The BL decomposing sample supported 11 fungal species representing 7 genera and their incidence, frequency and abundance were calculated and given in Table 1. In the initial days of incubation (May-June), the BL decomposing sample supported $H$. fuscoatra, $R$. rhizopodiformis, A. nidulans, M. pulchuella, A. fumigatus, Thermomyces lanuginosus, Torulla thermophila and A. flavus in a descending order. The highest incidence was recorded with Thermomyces lanuginosus followed by $H$. insolence. The least incidence was recorded with A. flavus, Torulla thermophila and Sporotrichum thermopilum. Rest of the species were recorded intermediate in their incidence. Thermomyces lanuginosus and Torulla thermophila were recorded with the highest frequency followed by A. nidulans, A. fumigates, A. flavus and $R$. rhizopodiformis which are similar in the percentage of frequency while differing in their incidence. The highest abundance was recorded again with Thermomyces lanuginosus followed by $R$. rhizopodiformis and A. nidulans. When compared with CDUB, the important thermophilic fungi such as Cheatomium thermophilum, C.v. coprophile, H. gresia, $M$. cinnamomea, $R$. arrhizus and $S$. thermophilum did not participate and thermotolerant fungi such as $A$. thermophilum was not found in BL decomposing sample.

The analysis of physico-chemical changes in the decomposing of the two samples (CDUB \& BL) is presented in Table 2.

The $\mathrm{pH}$ of the decomposing CDUB sample changed with the observation period. Generally, the dung of her- bivores will be of neutral $\mathrm{pH}$ (7.0). The changes were observed to increase up to 8.5 and a final $\mathrm{pH}$ of 7.3 was recorded at the end of the experiment. In the decomposing sample of banana leaf, $\mathrm{pH}$ was found to be fluctuating from 6.5 to 7.5 and later recorded as 7.0. These changes must be due to the involvement of different thermophilic coprophilous fungi (Fig. 1). The role of temperature plays is crucial in the process of decomposition. During the decomposition of CDUB sample, the temperature recorded in the range of $32^{\circ} \mathrm{C}$ to $50^{\circ} \mathrm{C}$ due to the presence of thermophilic fungi, while $36^{\circ} \mathrm{C}$ to $43^{\circ} \mathrm{C}$ was recorded during six months of $\mathrm{BL}$ decomposition period (Fig. 2).

During the decomposition of BL and CDUB, the ash and moisture content showed a gradual decrease in both the samples comparatively, the ash and moisture content was high in BL than CDUB at the end of the experiment, displaying utilization of substances by thermophilic fungi in CDUB sample.

A gradual change is observed in the percentage of humidity of BL and CDUB samples. As expected, the phosphorus content was also highest in CDUB $(65 \mu \mathrm{g})$ than BL $(55 \mu \mathrm{g})$ because of the percentage of rich nutritious dung. The organic carbon \% was higher in decomposing sample BL (6.8\%) than CDUB (6.5\%) sample.

\section{Succession on Sheep Dung}

The succession of thermotolerant and thermophilic copro-

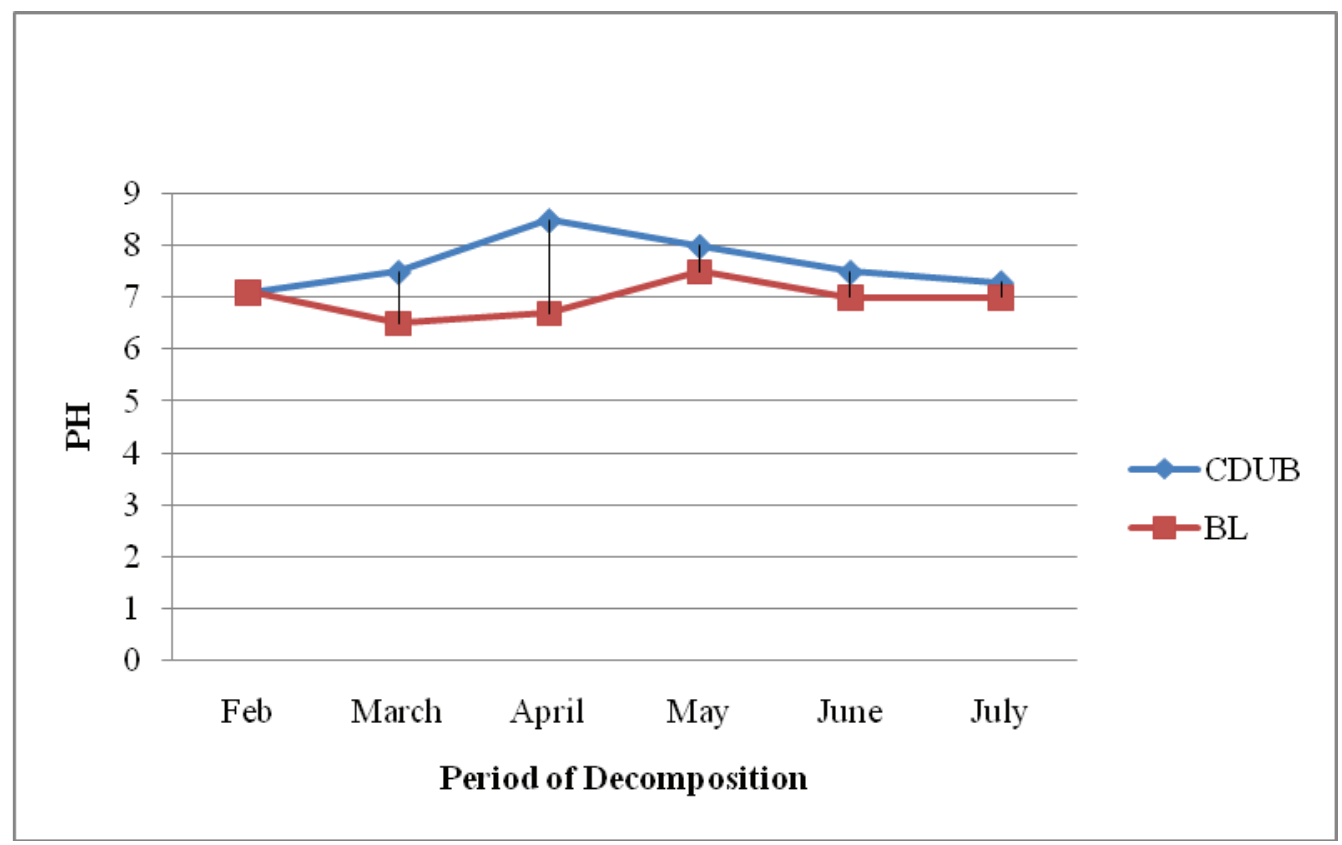

Fig. 1: $\mathrm{pH}$ changes during the CDUB and BL decomposition. 


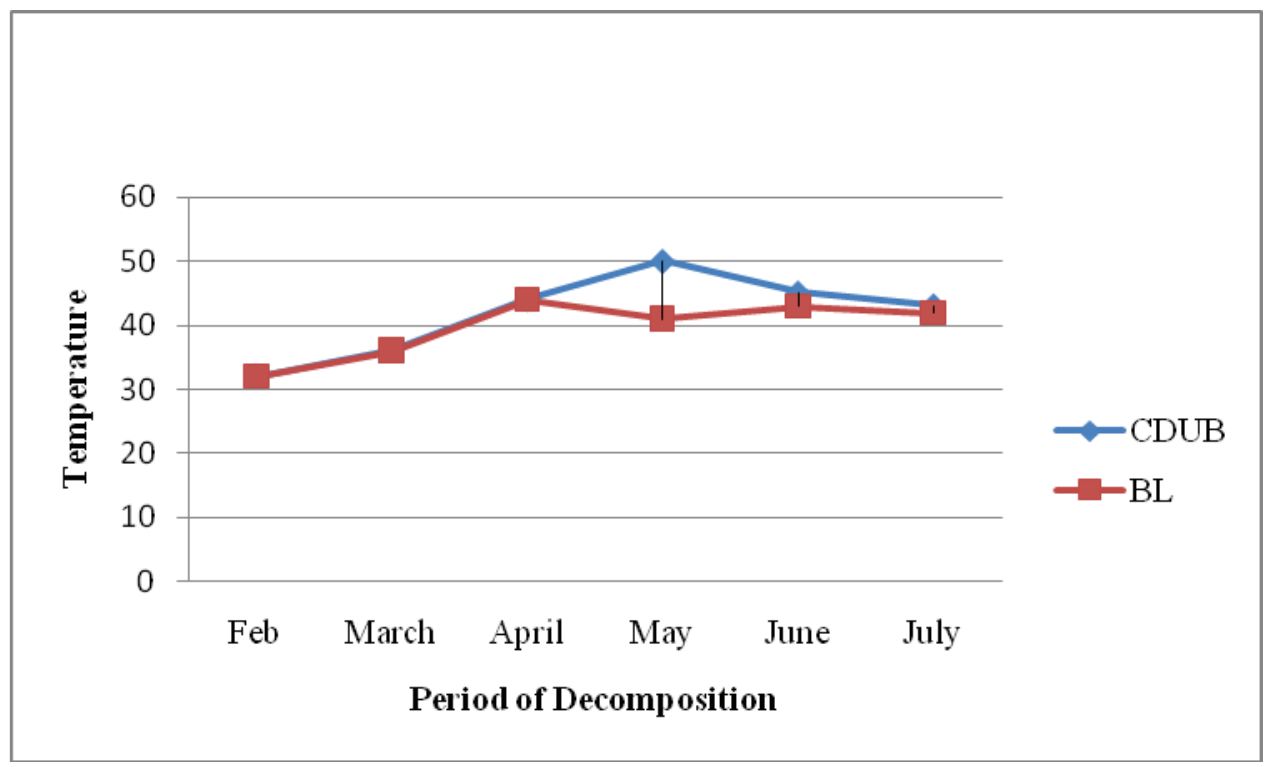

Fig. 2: Temperature changes during the decomposition of CDUB and BL.

Table 2: Physico-chemical changes in the decomposing mixture of cow dung, urine and banana leaf and banana leaf alone.

\begin{tabular}{|c|c|c|c|c|c|c|c|c|c|c|c|c|}
\hline \multirow[b]{2}{*}{ Month } & \multicolumn{2}{|l|}{ Feb } & \multicolumn{2}{|l|}{ March } & \multicolumn{2}{|l|}{ April } & \multicolumn{2}{|l|}{ May } & \multicolumn{2}{|l|}{ June } & \multicolumn{2}{|l|}{ July } \\
\hline & CDUB & BL & CDUB & BL & CDUB & $\mathrm{BL}$ & CDUB & BL & CDUB & BL & CDUB & $\mathrm{BL}$ \\
\hline Ash content $(\mathrm{g})$ & 0.26 & 0.29 & 0.24 & 0.25 & 0.21 & 0.24 & 0.19 & 0.23 & 0.18 & 0.23 & 0.17 & 0.2 \\
\hline Moisture (\%) & 88 & 89 & 80 & 83 & 80.4 & 80 & 70 & 76 & 69 & 65 & 58 & 60 \\
\hline Humidity (\%) & 73 & 75 & 83 & 81 & 98 & 99 & 93 & 80 & 80 & 78 & 70 & 75 \\
\hline Nitrogen $(\mu \mathrm{g})$ & 45 & 40 & 46 & 45 & 60 & 45 & 65 & 55 & 58 & 50 & 50 & 40 \\
\hline Organic carbon $(\%)$ & 13.4 & 12.4 & 25.8 & 19.7 & 10.3 & 17.2 & 7.8 & 16.3 & 6.7 & 12 & 6.5 & 6.8 \\
\hline Phosphorus $(\mu \mathrm{g})$ & 70 & 60 & 65 & 60 & 80 & 65 & 65 & 61 & 60 & 70 & 65 & 55 \\
\hline
\end{tabular}

philous fungi in in decomposing mixture of sheep dung and urine with banana leaf (SDUB), and banana leaf without dung (BL) sample were studied and their incidence, frequency and abundance are presented in Table 3. It reveals that the incidence of different fungi in decomposing SDUB and BL varied with the progress of decomposition. Among all the organisms studied, only 19 species representing 11 genera of fungi were involved in decomposing SDUB and BL. As the process progressed for SDUB decomposition, $H$. fuscoatra was recorded with the highest $\%$ of incidence followed by C. thermophile, M. cinnamomea, Scytalidium thermophilum and Thermomyces lanuginosus in a decreasing order. A. nidulans, H. insolens and Torulla thermophila showed their activity at initial stages only and later disappeared. A. terreus, $R$. arrizhus and Sporotrichum thermophilum occurred only in the second month of decomposition. The dynamics of $C$. thermophile may be in occurrence with temperature. The highest $\%$ of the incidence of $H$. fuscoatra was recorded at 5th month of the decomposition period. M. albomyces was recorded with a moderate percentage of incidence, while $H$. lanuginosus was detected only at the end of the decomposition period. Sporotrichum thermophilum was recorded with least incidence followed by A. terreus in SDUB decomposing sample. Cheatomium thermophilum, R. pusillus, M. cinnamomea and M. pulchuella were present in decreasing order.

During banana leaf (BL) decomposition incidence of important thermophilic fungi like A. terreus, $C$. thermophilum, H. grisea, M. cinnamomea, M. pulchuella, Myriococcum albomyces, S. thermophilum, T. duponti and R. arrhizus, was not observed as in SDUB decomposition sample. Whereas 
A. fumigatus, A. flavus and $R$. podiformis were not recorded during the decomposition of SDUB but observed during decomposition of BL.

The highest $\%$ of incidence was recorded with Thermomyces lanuginosus followed by $H$. insolens, $H$. fuscoatra, $M$. pulchuella and $R$. podiformis in a decreasing order. $A$. flavus was recorded with least incidence, while others with moderate incidence.

The highest $\%$ of frequency was recorded with $T$. lanuginosus followed by T. thermophila. Sporotrichum thermopilum was recorded with least incidence followed by A. terreus in SDUB decomposing sample. C. thermophile was again recorded with the highest $\%$ of abundance followed by $R$. pusillus, M. cinnamomea and M. pulchuella in a decreasing order.

During Banana leaf BL decomposition, the incidence of important thermophilic fungi like A. terreus, C. thermophilum, $H$. grisea, M.cinnamomea, Myriococcum albomyces, $S$. thermophilum, T. duponti and $R$. arrhizus was not observed as in SDUB decomposing sample. Whereas A. fumigatus, A. flavus and $R$. podiformis were not recorded during decomposition of SDUB, but observed during decomposition of BL. The highest $\%$ of incidence was recorded with Thermomyces lanuginosus followed by $H$. insolens, $H$. fuscoatra, M. pulchuella and $R$. podiformis in decreasing order. A. flavus was recorded with least incidence, while others with moderate incidence.

The highest per cent of frequency was recorded with $T$. lanuginosus followed by $T$. thermophila and sterile mycelium.

If we compared both SDUB and BL decomposing sam- ples, important thermophilic fungi like C. thermophile, $M$. cinnamomea, $R$. arrizhus and $S$. thermophilum were absent in BL decomposing sample.

The physico-chemical analysis of decomposing sample SDUB and BL were analysed and presented in Table 4.

Initially, the $\mathrm{pH}$ of SDUB sample was recorded as 7.2 and as the process progressed it varied between $\mathrm{pH} 7.2$ to 8.0 and a final $\mathrm{pH}$ of 7.5 was recorded at the end of the decomposition period. During the decomposition period of banana leaf (BL), the $\mathrm{pH}$ ranged from 7.2 to 8.0 and the final $\mathrm{pH}$ was observed at 7.5 during decomposition of SDUB. The $\mathrm{pH}$ values varied from 7.1 to 7.5 and finally, a neutral $\mathrm{pH}$ (7.0) was recorded (Fig. 3). The temperature has a crucial role to play in the process of decomposition. During the decomposition of SDUB sample, the temperature recorded was in the range of $37^{\circ} \mathrm{C}$ to $51^{\circ} \mathrm{C}$ due to the presence of thermophilic fungi, while it was observed between $36^{\circ} \mathrm{C}$ to $42^{\circ} \mathrm{C}$ during the six months of BL decomposition period (Fig. 4).

The ash and moisture content gradually decreased during the process of decomposition of SDUB and BL. Comparing both the samples, the ash content and moisture of BL were relatively higher than in SDUB sample which shows more utilization by thermophilic fungi in SDUB sample. Humidity was gradually higher in the middle of the decomposition period (99\%) and later decreased to $75 \%$ and $76 \%$ in $\mathrm{BL}$ and SDUB samples respectively.

The total nitrogen and phosphorus contents were increased in SDUB samples and decreased in BL. The organic carbon percentage was higher in BL $(6.2 \%)$ than in SDUB

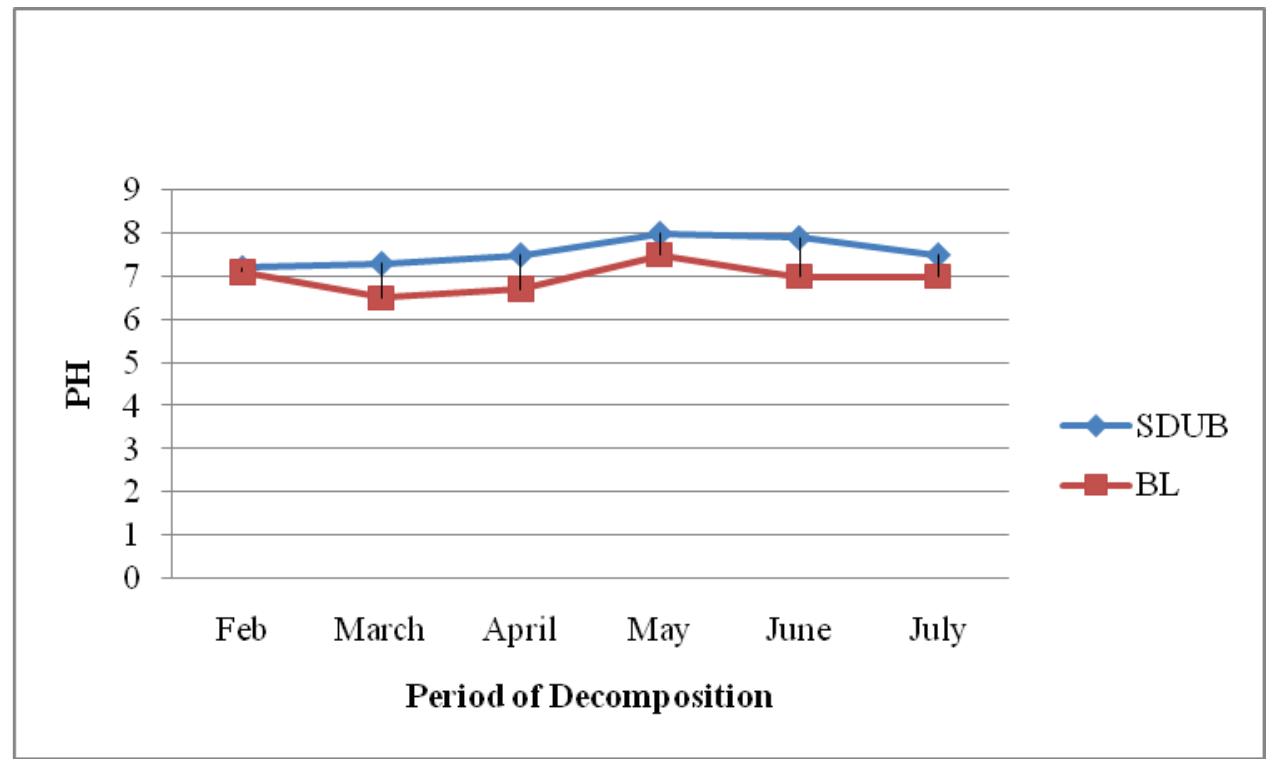

Fig. 3: $\mathrm{pH}$ changes during the decomposition of SDUB and BL. 


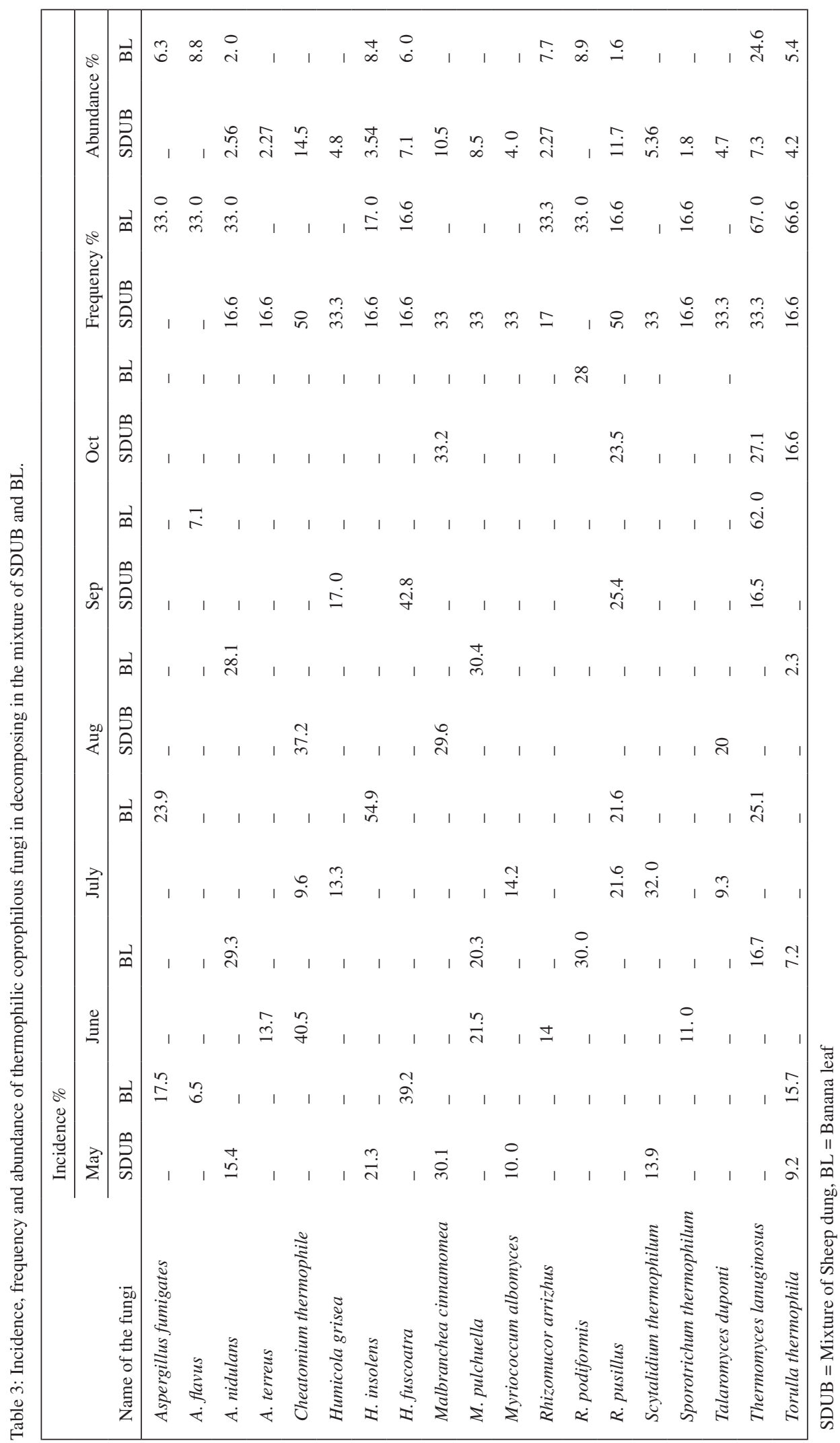




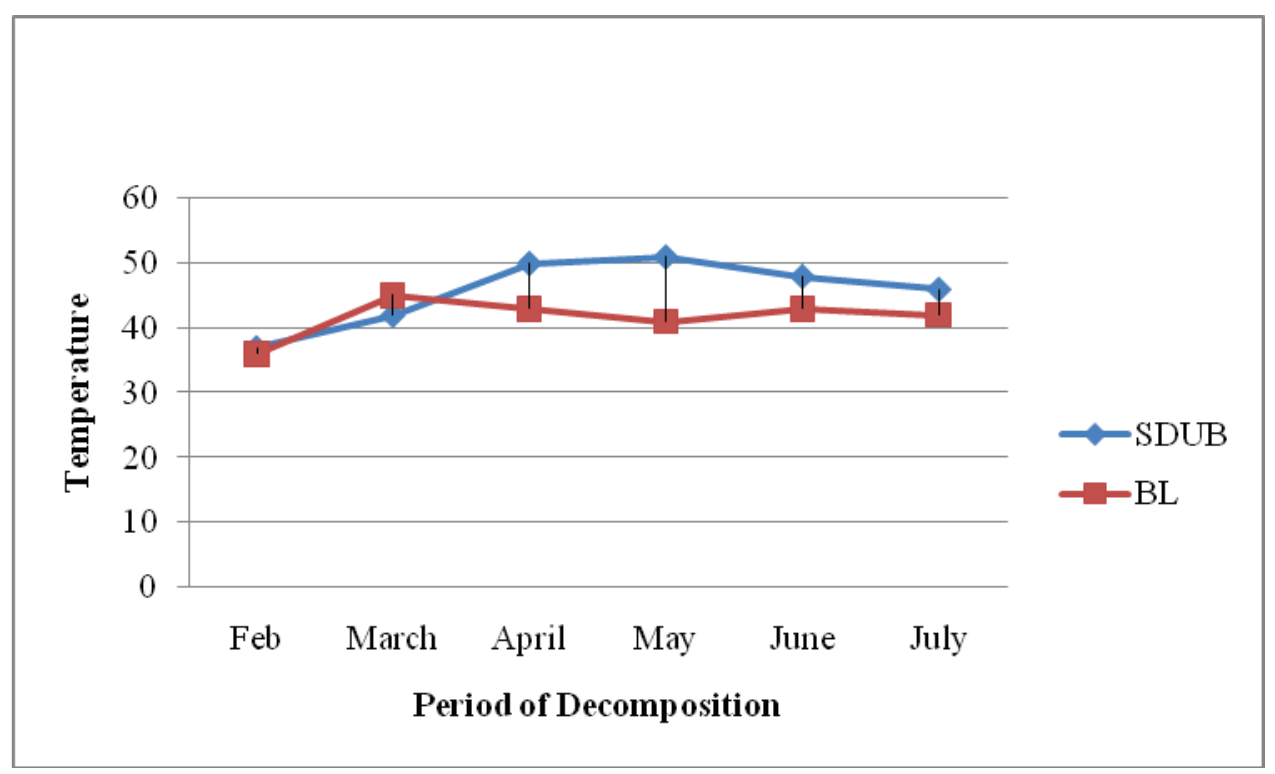

Fig. 4: Temperature changes during the decomposition of SDUB and BL.

Table 4: Physico-chemical changes in the decomposing mixture of sheep dung, urine and banana leaf and banana leaf alone.

\begin{tabular}{|llllllllllllll}
\hline Month & Feb & & March & & April & & May & & June & July \\
\hline & SDUB & BL & SDUB & BL & SDUB & BL & SDUB & BL & SDUB & BL & SDUB & BL \\
\hline Ash content $(\mathrm{g})$ & 0.27 & 0.29 & 0.23 & 0.25 & 0.21 & 0.24 & 0.22 & 0.23 & 0.19 & 0.23 & 0.18 & 0.21 \\
Moisture $(\%)$ & 74 & 89 & 80 & 83 & 76 & 80 & 65 & 76 & 56.4 & 65 & 54 & 60 \\
Humidity $(\%)$ & 74 & 75 & 80 & 81 & 99 & 99 & 85 & 80 & 81 & 78 & 76 & 75 \\
Nitrogen $(\mu \mathrm{g})$ & 50 & 40 & 45 & 45 & 59 & 45 & 63 & 55 & 60 & 50 & 55 & 40 \\
Organic carbon $(\%)$ & 12.4 & 12.4 & 19.8 & 19.7 & 22.7 & 17.2 & 14.6 & 16.3 & 9.4 & 12 & 6.2 & 6.8 \\
Phosphorus $(\mu \mathrm{g})$ & 65 & 60 & 70 & 60 & 75 & 65 & 71 & 61 & 65 & 70 & 61 & 55 \\
\hline
\end{tabular}

(6.8\%) whereas phosphorus content was higher in SDUB $(61 \mu \mathrm{g})$ than BL $(55 \mu \mathrm{g})$ decomposing sample.

\section{CONCLUSIONS}

During this study, significant changes were observed in different physio-chemical properties of decomposing material which focuses particularly on the role of thermophilic coprophilous fungi in reducing the time for decomposition. It also gives a clear demonstration of various effects of different environmental conditions on the microbial population during the process of decomposition. The decomposition product thus obtained was found to be rich in organic phosphorus and nitrogen, raising the hopes for a successful implementation of it in daily agricultural practices.

\section{ACKNOWLEDGEMENT}

Authors are thankful to the Head, Department of Micro- biology, Kakatiya University and Palamuru University for providing the necessary facilities.

\section{REFERENCES}

Atkinson, R.B., Zipper, C., Daniels, W.L. and Cairns, J. Jr 1997. Constructing wetlands during reclamation to improve wildlife habitat. Reclamation Guidelines for Surface Mined Land in Southwestern Virginia. Powell River Project-Virginia Cooperative Extension Publication, 460-129.

Bailey, S.W. and Hornbeck, J.W. 1992. Lithologic composition and rock weathering potential of forested, glacial-till soils. Res. Pap. NE-662. U.S. For. Serv., Northeastern For. Exp. Stn., Radnor, PA.

Beffa, T., Blanc, M., Lyon, P. F., Vogt, G., Marchiani, M., Fischer, J.L. and M. Arango, 1996. Isolation of Thermus strains from hot composts (60 to 80 degrees C). Appl. Environ. Microbiol., 62: 1723-1727.

Cooney, D.C. and Emerson, R. 1964. Thermophilic fungus: An Account of their Biology, Activities, and Classification. W.H. Freeman and Co., San Francisco, pp. 1-188.

Donkova, R., Stoichkova, M. and Slavov, D. 2008. Dynamic of microbial population during composting of organic wastes. International Confer- 
ence- Potential for Simple Technology Solutions in Organic Manure Management, Albena, Bulgaria, pp. 409-413.

Ghaudhry, A., Chaudhry, N., Naeem, M.A., Jilani, G., Razzaq, A., Dong-Mei Zhang, Azeem, M. and Ahmed, M. 2013. Influence of composting and poultry litter storage methods on mineralization and nutrient dynamics. The Journal of Animal and Plant Sciences, 23: 500-506.

Hankin, L., Poincelot, R.P. and Anagnostakis, S.L. 1975. Microorganisms from composting leaves: Ability to produce extracellular degradative enzymes. Microbial Ecology, 2(4): 296-308.

Sofia, Duarte, Claudia Pascoal and Fernanda Cassio 2009. Functional stability of stream dwelling microbial decomposers exposed to copper and zinc stress. Freshwater Biology, 54: 1683-1691

Jianru, Shi 2013. Decomposition and Nutrient Release of Different Cover Crops in Organic Farm Systems. Dissertations \& Theses in Natural Resources, 6.

Joshi, P. and Thakre, R.P. 1991. Composting of leafy biomass into farm manure. Proceedings of the seventh international conference on solid waste management and secondary materials. 3B: Philadelphia PA, USA.

Liu, P., Huang, J., Han, X., Sun, O.J. and Zhou, Z. 2006. Differential responses of litter decomposition to increased soil nutrients and water between two contrasting grassland plant species of Inner Mongolia, China. Applied Soil Ecology, 34: 266-275.

Manoharachary, C., Kunwar, I.K. and Rajithasri Kavaka, A.B. 2014. Advances in applied mycology and fungal biotechnology. KAVAKA, 43: 79-92.

Masunga, G., Andresen, S., Taylor, J.E. and Dhillion, S.S. 2006. Elephant dung decomposition and coprophilous fungi in two habitats of semi-arid Botswana. Mycology Research, 110(10): 1214-1226.
Mouchacca, J. 1997. Thermophilic fungi: Biodiversity and taxonomic status. Cryptogamie Mycologie, 18: 19-69.

Richardson, M. J. 2002. The coprophilous succession. Fungal Diversity, 10: 101-111.

Ross, R.C. and Harris, P.J. 1983. The significance of thermophilic fungi in mushroom compost preparation. Sci. Hortic. (AMST), 20: 61-70.

Rosenberg, S.L. 1975. Temperature and $\mathrm{pH}$ optima for 23 species of thermophilic and thermotolerant fungi. Canandian J. Microbiol., 21: 1535-1540.

Swift, M.J., Heal, O.W. and Anderson, J.M. 1979. Decomposition in Terrestrial Ecosystems. Univ. of California Press.

Vijay, B. and Pathak A. 2014. Exploitation of thermophilic fungi in compost production for white button mushroom (Agaricus bisporus) cultivation-A Review. In: Proceedings of the 8th International Conference on Mushroom Biology and Mushroom Products (ICMBMP8), pp. 19-22.

Viji, J. and Neelanarayanan, P. 2015. Effect of different animal manure on vermicomposting of mixed leaves litter by utilizing an exotic earthworm. International Journal of Advanced Research, 3(7): 1360-1376.

Waksman, S.A. and Cordon, T.C. 1939. Thermophilic decomposition of plant residues in composts by pure and mixed cultures of micro-organismsms. Soil Sci., 47: 217-224.

Ward, G.M. and Johnston, F.B. 1962. Chemical Methods of Plant Analysis. Publ. Research Branch., Canada Dept. Agric., Ottawa

Webster, J. 1970. Presidential Address. Coprophilous Fungi. Transactions of the British Mycological Society, 54: 161-180.

Wolf, B. 1947. Determination of nitrate, nitrite and ammonium nitrogen. Rapid photometric determination in soil and plant extracts. Industr. Engg. Chem., (Anal., ed.), 16: 446. 